\title{
EDITORIAL
}

\section{How to make an alveolus}

\author{
E.R. Weibel
}

$\triangle 1$ lveoli are the hallmark of lung structure. In 1959, when I embarked on studies of lung structure that "should interest physiologists", the first question I was asked was "how many alveoli are there in the human lung?" Along with Prof. D. Gomez, I counted alveoli by devising a now obsolete method [1], only to realise that what is of real functional importance is the design of the wall of these small chambers, such as their surface area and their provision with capillaries [2]. However, the fascination with the notion of alveoli has remained, and a new unbiased method for counting them has now shown that the human lung is made of $\sim 480$ million of these small bubbles [3], all openly connected to the terminal branches of the airway tree that constitute the pulmonary acinus.

Alveoli are formed to increase the density of gas exchange surface on the acinar airway tree, thus facilitating diffusion of oxygen to and into the capillaries. But to what extent is an alveolus a structural entity? This question is pertinent if we try to interpret the statement by FEHRENBACH et al. [4] in this issue of the European Respiratory Journal, that "neoalveolarisation contributes to compensatory lung growth following pneumonectomy". This suggests that new alveoli "pop up" when the residual lung grows its surface to compensate for the loss of gas exchange tissue caused by partial pneumonectomy in mice [5]. The study by FeHRENBACH et al. [4] indeed shows convincingly that the number of alveoli has increased by $\sim 50 \%$, from 643,000 to 925,000 in the right lung, 20 days after left pneumonectomy. This increase reflects part of the compensatory growth process that was found to fully restore the lost gas exchange surface [5].

The compensatory growth process following partial pneumonectomy first implies that additional tissue and new capillaries are formed in response to the stretching of alveolar septa and blood vessels as the residual lung expands to fill the intrathoracic space that is liberated by the excised part of the lung [6]. It has been shown that in adult dog lungs this occurs only if more than half of the lung is removed, whereas there is no evidence of true tissue growth after left pneumonectomy that removes only $\sim 40 \%$ of the lung [7, 8]. In contrast, immature lungs have a strong potential for compensatory growth [9]. It appears that the lung of small rodents (rats and mice) retains a potential for compensatory growth even into adulthood [5, 10]. In the study of mice by FEHRENBACH et al. [4], the left lung was resected, which constitutes $30 \%$ of total lung

\section{STATEMENT OF INTEREST: None declared.}

CORRESPONDENCE: E.R. Weibel, Institute of Anatomy, University of Berne, Baltzerstrasse 2, CH3000 Berne 9, Switzerland. Fax: +41 313024503. E-mail: weibel@ana.unibe.ch volume; expansion of the residual lung into the liberated space was accompanied by a complete restoration of the gas exchange surface by cell proliferation and tissue growth [5]. A subsequent question is then how to accommodate this new surface area within the limited space of the thoracic cavity. The study by FEHRENBACH et al. [4] shows that this involves creating new alveoli, thus restoring not only the surface area but also its topology, at least in part.

Therefore, the key issue is how new alveoli can be made. Neoalveolarisation implies that the alveolus is a unit that can be formed de novo by some morphogenetic process, also in the mature lung. But is this so? Neoformation of alveoli occurs during morphogenesis when the primitive saccules are transformed, as a burst process, into alveolar ducts by pulling down a set of tissue septa with a single capillary network towards the axis of the duct [11]. At first there are no alveoli. The primitive saccules, the peripheral segments of the airway tree, are separated by thick septa which contain two capillary networks, one for each saccule, and a rather thick connective tissue core. On day 3 post-natally in the rat, ridges form on the saccular surface associated with strong fibre bundles, which appear to "pull" the ridge into the air space taking along a single capillary network. These fibre bundles form the free edge of the alveolar septa and are segments of a network whose meshes are alveolar openings. This network marks the border between the alveolar duct and its sleeve of densely packed alveoli (fig. 1a).

Thus, the key event in this process is the formation of alveolar septa, which are very thin and contain a single dense capillary network (figs $1 \mathrm{~b}$ and $\mathrm{c}$ ). The septum is supported by a fine network of septal fibres that are interwoven with the capillaries and anchored at both ends (fig. 1c): 1) in the axial fibres that form the network of alveolar entrance rings in the wall of alveolar ducts; and 2) in the peripheral fibres that extend through interlobular septa towards the pleura [12-15]. This allows the spreading of the capillaries by mechanical tension on the fibres. Because of this disposition of capillaries and fibres, alveoli in the mature lung are not structural units that can be separated: each of their walls is shared by two adjoining alveoli, both in terms of gas exchange with the capillary and with respect to mechanical support. Even the epithelial lining is shared by two adjacent alveoli as it extends through the pores of Kohn (figs $1 b$ and $c$ ). This may perhaps sound like semantics, but it is highly pertinent to the topic of neoalveolarisation in relation to compensatory growth of the alveolar surface. This disposition of the fibre system makes the lung a tensegrity structure [16], which means that, in terms of mechanics, the integrity of lung parenchymal structure is exclusively ensured by the tension of the fibre continuum that 

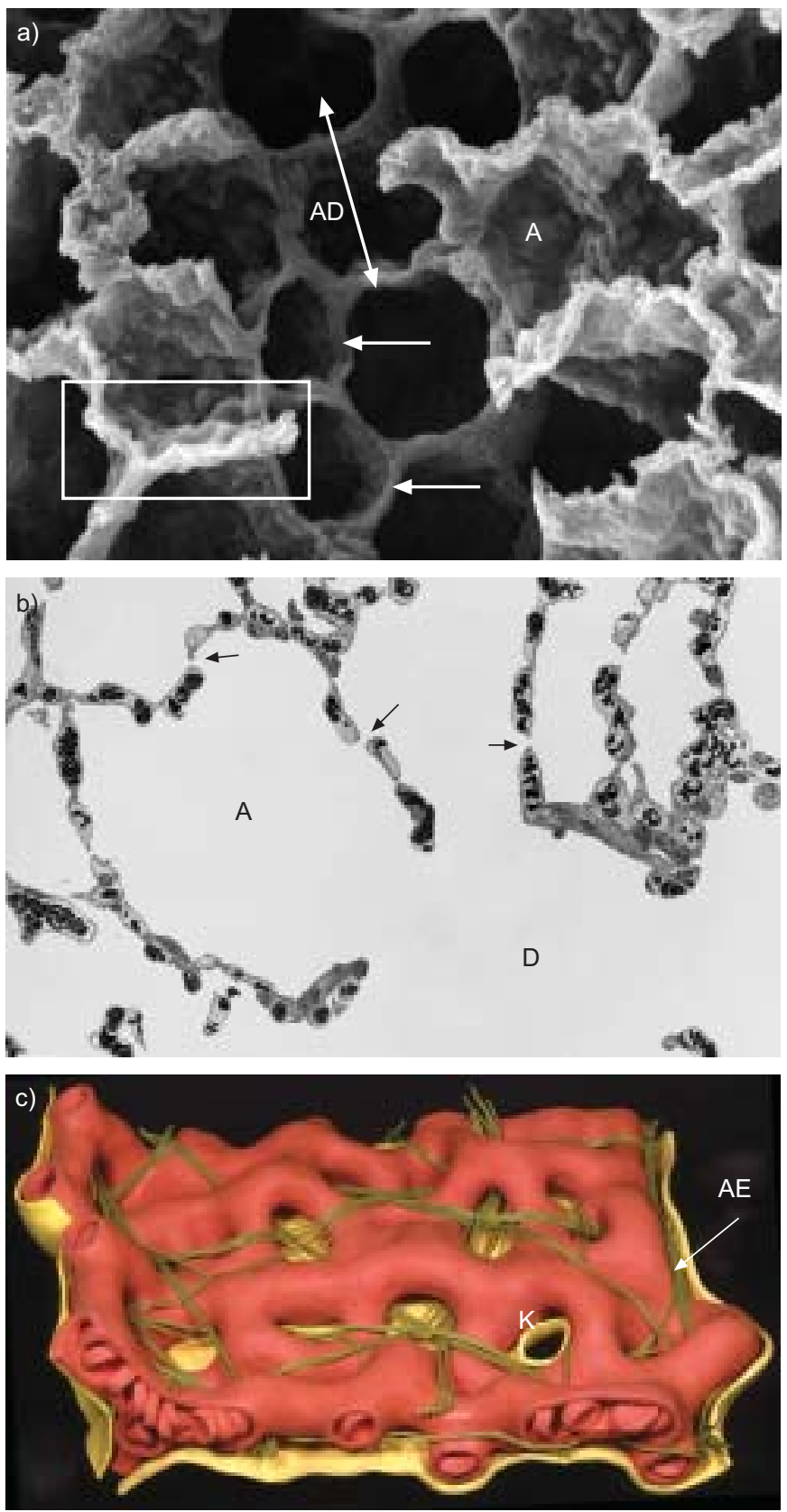

FIGURE 1. a) Scanning electron micrograph of rabbit lung showing alveolar duct (AD) with the network of alveolar entrance rings (double-ended arrow) and some alveoli (A) with septa cut across. The parallel arrows mark the direction of the duct. The area in the box is the alveolar septum. b) Transmission electron micrograph of dog lung showing very thin septa separating alveoli (A) attached to the strong entrance ring fibres, partly with smooth muscle, at the boundary of the duct (D). Pores of Kohn are seen as gaps in the septum (arrows). c) Model of the alveolar septum showing the capillary network (red area) interwoven with fibres (green) that are anchored in strong fibre strand at the septal border forming an alveolar entrance ring (AE). The pore of Kohn (K) shows that alveolar epithelium (yellow) extends across the pore to the neighbouring alveolus.

supports alveolar walls and their capillaries [12, 13, 15]. If one fibre is cut, this causes collapse of the septum followed by rearrangement of the adjacent parts, as occurs in emphysema.
Therefore, the question is: how can new alveoli be formed within such a system where the continuity of the fibre tension system cannot be broken and the capillary network must be also remain intact?

The most direct way is to recapitulate developmental morphogenesis and to "pull down" a new septum from the deep wall of an alveolus by the making of a strong fibre bundle as part of the septal fibre network, which then becomes integrated into the network of alveolar entrance rings; a process that can be conceived as a continuum without disruption of the fibre system [17]. In the course of this process the capillary network can expand, also without disruption, by the process of intussusceptive growth [18] This neoformation of an alveolar septum leads to the splitting of a pre-existing alveolus into two alveoli each with an entrance ring, thus, adding a mesh to the wall network of the alveolar duct system and increasing its Euler number. At this point, it is worth noting that in the study by FEHRENBACH et al. [4], the number of meshes in the alveolar duct wall is counted as a proxy for alveoli, totally compatible with this morphogenetic process, and using an unbiased stereological method.

Of course, the question remains whether other processes can contribute to the growth of alveolar surface and the addition of new alveoli. It has been shown that in post-natal growth the gas exchange region grows fastest at the periphery or near the pleura [19]. Therefore, it cannot be excluded that there are regions where the post-natal morphogenetic processes can be recapitulated preferentially as well as in post-pneumonectomy compensatory growth, such as in the subpleural region where FOSTER et al. [20] demonstrated higher proliferative activity.

The most important question is whether compensatory growth also involves the formation of new alveolar ducts, and not just new alveoli on pre-existing ducts, because these would then have to be enlarged in length and possibly in diameter as well. This is important due to the effect of acinar airway design on oxygen supply to the most peripheral alveoli [21, 22]. It has indeed been shown that, in the dog lung, respiratory bronchioles can be multiplied [23], particularly in the immature lung, which suggests that compensatory neoalveolarisation, as described herein, may be part of a more complex effort on the part of the residual lung to re-establish favourable conditions for gas exchange after loss of a significant part of functional lung tissue. The quest for what is really happening in compensatory lung growth can go on.

\section{REFERENCES}

1 Weibel ER, Gomez DM. A principle for counting tissue structures on random sections. J Appl Physiol 1962; 17: 343-348.

2 Weibel ER, Gomez DM. Architecture of the human lung. Science 1962; 137: 577-585.

3 Ochs M, Nyengaard JR, Jung A, et al. The number of alveoli in the human lung. Am J Respir Crit Care Med 2004; 169: 120-124.

4 Fehrenbach H, Voswinckel R, Michl V, et al. Neoalveolarisation contributes to compensatory lung growth following pneumonectomy in mice. Eur Respir J 2008; 31: 515-522. 
5 Voswinckel R, Motejl V, Fehrenbach A, et al. Characterisation of post-pneumonectomy lung growth in adult mice. Eur Respir J 2004; 24: 524-532.

6 ad hoc Statement Committee, American Thoracic Society. Mechanisms and limits of induced postnatal lung growth. Am J Respir Crit Care Med 2004; 170: 319-343.

7 Hsia CC. Signals and mechanisms of compensatory lung growth. J Appl Physiol 2004; 97: 1992-1998.

8 Hsia CCW. Quantitative morphology of compensatory lung growth. Eur Respir Rev 2006; 15: 148-156.

9 Takeda S, Hsia CC, Wagner E, Ramanathan M, Estrera AS, Weibel ER. Compensatory alveolar growth normalizes gasexchange function in immature dogs after pneumonectomy. J Appl Physiol 1999; 86: 1301-1310.

10 Wandel G, Berger LC, Burri PH. Morphometric analysis of adult rat lung after bilobectomy. Am Rev Respir Dis 1983; 128: 968-972.

11 Burri PH. Structural aspects of postnatal lung development-alveolar formation and growth. Biol Neonate 2006; 89: 313-322.

12 Weibel ER, Gil J. Structure-function relationships at the alveolar level. In: West JB, ed. Bioengineering Aspects of the Lung. Marcel Dekker, New York, 1977; pp. 1-81.

13 Weibel ER, Bachofen $H$. The fibre scaffold of lung parenchyma. In: RG Crystal, JB West, ER Weibel, PJ Barnes, eds. The Lung: Scientific Foundations. 2nd Edn. Vol. 1. LippincottRaven Publishers, Philadelphia, 1997; pp. 1139-1146.

14 Wilson TA, Bachofen H. A model for the mechanical structure of the alveolar duct. J Appl Physiol 1982; 52: 1064-1070.
15 Weibel ER. Functional morphology of lung parenchyma. In: PT Macklem, J Mead, eds. Handbook of Physiology. Section 3: The Respiratory System. Vol III. Part 1. American Physiological Society, Bethesda, 1986; pp. 89-111.

16 Fuller RB. Tensegrity. Portfolio Artnews Annual 1961; 4 : 112-127.

17 Oldmixon EH, Butler JP, Hoppin FG Jr. Lengths and topology of alveolar septal borders. J Appl Physiol 1989; 67: 1930-1940.

18 Burri PH, Djonov V. Intussuceptive angiogenesis-the alternative to capillary sprouting. Mol Aspects Med 2002; 23: Suppl. 6, S1-S27.

19 Massaro GD, Massaro D. Postnatal lung growth: evidence that the gas-exchange region grows fastest at the periphery. Am J Physiol 1993; 265: L319-L322.

20 Foster DJ, Yan X, Bellotto DJ, et al. Expression of epidermal growth factor and surfactant proteins during postnatal and compensatory lung growth. Am J Physiol Lung Cell Mol Physiol 2002; 283: L981-L990.

21 Sapoval B, Filoche M, Weibel ER. Smaller is better-but not too small: a physical scale for the design of the mammalian pulmonary acinus. Proc Natl Acad Sci USA 2002; 99: 10411-10416.

22 Weibel ER, Sapoval B, Filoche M. Design of peripheral airways for efficient gas exchange. Respir Physiol Neurobiol 2005; 148: 3-21.

23 Hsia CCW, Zhou XS, Bellotto DJ, Hagler HK. Regenerative growth of respiratory bronchioles in dogs. Am J Physiol Lung Cell Mol Physiol 2000; 279: L136-L142. 